\title{
One approach to the study of gas pricing based on gas supply systems modelling (the case of Northeast Asia)
}

\author{
Sergei P. Popov ${ }^{1}$ and Darya V. Maksakova ${ }^{1 *}$ \\ ${ }^{1}$ Melentiev Energy Systems Institute of Siberian Branch of Russian Academy of Sciences, Irkutsk, Russia
}

\begin{abstract}
The article deals with the approach to gas pricing analysis based on the use of optimization models of gas supply systems. The object of the study is the Northeast Asian gas market. The model of the excessive gas supply system in Northeast Asia is described. The primal problem of the model is to minimize the sum of gas production and transportation costs under the infrastructure constraints. The solutions to the primal problem are the volumes of gas produced in each production point and transported via each route. The solutions to the dual problem (dual variables or shadow prices) are node prices in the points of gas supply system, the producers' rent and the transporters' rent. It is highlighted that the dual analysis plays an important role. It allows evaluating price relations between the points of gas supply system, identifying export routs characterized by the highest rent, evaluating the competitiveness of suppliers in the different scenarios of technological development, energy policy and market environment. The analytical capacities of the dual analysis are illustrated by the study of the impact of "unconventional" gas development in the importing countries on the Northeast Asian gas market environment. When the costs of unconventional gas production rise, gas trade patterns change, more competitive players enter the market, and gas prices in all consumption points as well as producers' rents increase. It is concluded that if importers seek to lower import dependency while keeping the same price level, they have to lower the costs of unconventional gas production by technological development and/or to subsidize the industry to make it more competitive.
\end{abstract}

\section{Inroduction}

Northeast Asia (NEA) plays an important role in a global gas market. Japan, the Republic of Korea, and China are the biggest consumers and importers of liquefied natural gas (LNG). China is a main driver of the global gas market growth; the reasons are the low current level of the share of gas in total primary energy supply and the policy of coal to gas switching caused by ecological concerns. Mongolia has also some prospects for gas consumption growth due to the need for reducing air pollution in Ulaanbaatar. A favorable environment for gas consumption can appear in DPRK, if geopolitical tension is lowered and rapid social and economic development takes place.

The abundance of natural gas recourses and the economical-geographical location predetermine the role of Russia in the region as a natural gas exporter. Today Russian export of LNG to the other countries of NEA is based on Sakhalin II and Yamal LNG projects. In the end of 2019 the supply of gas to China through the "Power of Siberia" pipeline is starting. New projects, which can ensure Russian LNG export growth to the NEA region, include the production and liquefaction of gas in the Arctic and on Sakhalin. Possible routes of the future gas pipeline export from Russia to the NEA region are export from the Sakhalin gas fields to China and the Korean Peninsula through the existing Sakhalin-Khabarovsk-Vladivostok pipeline as well as the construction of a new pipeline linking Sakhalin with Hokkaido and new pipelines linking Siberian gas fields with China.

Nowadays the formation of a global gas market, where international natural gas pipelines and LNG connect regional and countries' gas supply systems with each other, is taking place. New opportunities for gas supply routes, supply sources and markets diversification are appearing. The similar process, caused by the development of gas transportation infrastructure and gas transportation technologies, can be observed in NEA at the regional level. So, when a highly competitive gas market is formed, import prices in the NEA region will be determined by the interplay of supply and demand coming from many buyers and sellers. Market prices in trading centers (hubs) will be a benchmark for the participants of the Northeast Asian gas market. These prices will influence suppliers' competitiveness and the efficiency of export routes. 


\section{The methodology}

The process of price formation in energy markets is described and simulated by different types of mathematical models. For instance, econometric models identify and describe the relationship between a resulting indicator and factors, which cause its variance. Optimization models are used to identify the best solution (i.e. the solution that maximizes/minimizes the objective function) within a set of possible ones. When energy markets and energy pricing are simulated, different models are usually used; the outputs of one model become the inputs of other ones.

There are the examples of well-developed non-linear (Institute of Energy Economics COLUMBUS Global Gas Market Model [1], The Baker Institute World Gas Trade Model [2]) and linear (US Energy Information Administration International Natural Gas Model [3], NEXANT World Gas Model [4;5], ERI RAS World Gas Model [6, pp. 105-117], ESI RAS Unified Gas Supply System (UGSS) of Russia Model [7, pp.131-144] etc.) optimization models of gas markets. These models differ according to the geographical scope, the objective function and the constraints, the level of detail and the input parameters. NEXANT World Gas Model, ERI RAS World Gas Model, ESI RAS UGSS of Russia Model minimize gas production, storage and transportation costs subject to infrastructure (NEXANT World Gas Model, ERI RAS World Gas Model, ESI RAS UGSS of Russia Mod-el) and contract (NEXANT World Gas Model, ERI RAS World Gas Model) constraints. Contract prices in NEXANT World Gas Model, ERI RAS World Gas Model are calculated outside of the models on the basis of crude oil and petroleum products prices; spot prices are evaluated in the models as a result of the optimization. ESI RAS UGSS of Russia Model evaluates the level and the structure of marginal node prices of gas, which are the solutions to the dual problem of optimal resource allocation.

International Research Center "Energy infrastructure in Asia" ESI RAS developed Gas Infrastructure Development in the East Asian Region (GEAR) model to calculate competitive Ex Works prices of gas exporters to NEA [8]. Here this model was expanded to grid linear programming model. A mathematical description of the model is as follows:

$$
\begin{gathered}
f(x)=\sum_{i \in E} c_{i} x_{i}+\sum_{j \in I} \sum_{i \in I} c_{i j} x_{i j} \rightarrow \min \\
x_{i}+\sum_{j \in I} a_{j i} x_{j i}-\sum_{j \in I} x_{i j}-d_{i} \geq 0 ; i \in E \\
\sum_{i \in I} a_{i j} x_{i j}-\sum_{i \in I} x_{j i}-d_{j} \geq 0 ; j \in I \\
0 \leq x_{i} \leq e_{i} ; i \in E \\
0 \leq x_{i j} \leq r_{i j} ; i, j \in I
\end{gathered}
$$

Sets:

$I-$ set of nodes
$E \subset I-$ set of production nodes

Outputs:

$x_{i}$ - gas production volumes in node $i \in E$

$x_{i j}$ - gas transportation volumes from node $i$ to node $j$;

$i, j \in I$

Inputs:

$c_{i}$ - gas production costs in node $i \in E$

$c_{i j}-$ costs to transport gas from node $i$ to node $j ; i, j \in I$

$d_{i}\left(d_{\mathrm{j}}\right)$ - the need for imports in node $i(j) \in I$

$e_{i}$ - maximum production volumes in node $i \in E$

$r_{i j}$ - maximum transportation volumes from node $i$ to node $j ; i, j \in I$

$a_{i j}-$ loss coefficient when transporting gas from node $i$ to node $j ; i, j \in I$. When there are no transportation losses $a_{i j}=1$.

The optimization criterion (1) is to minimize the sum of gas production and transportation costs (including liquefaction and regasification costs in case of LNG). The model has three types of nodes: gas production points, gas consumption points and regasification terminals. Gas demand is aggregated in the following nodes: Beijing, Harbin, Wuhan, Hong Kong, Tokyo, Seoul and Ulaanbaatar. Gas production points are Kovykta and Chayanda fields, shelf of Sakhalin Island, the coast of the Gulf of Mexico (the USA), Pacific coast of Canada, Australia's continental shelf, the Gulf of Papua, Central Asia gas fields, the coasts of West (Nigeria) and East (Mozambique) Africa, the Persian Gulf (Qatar and Iran). The constraints are maximum annual production volumes in the production points (4), maximum transportation volumes for each route (5) and balance constraints (2-3): the sum of production volumes and gas inflows to the node cannot exceed the sum of gas consumption volumes in the node and gas outflows from it.

The solutions to problem (1)-(5) are optimal (from a cost point of view) volumes of gas produced in each node and transported via each route. It is assumed, that the market is perfectly competitive. In this case the resource allocation is achieved through a market pricing mechanism, and the suppliers that have the lowest production and/or transportation costs receive additional rent revenues.

The solutions to the problem dual to the problem of optimal resource allocation (dual or shadow prices) value scarcity of resources and can be interpreted as rent. Dual prices were introduced by L. V. Kantorovich, who jointly with T. C. Koopmans was awarded Nobel Prize in Economic Sciences "for their contributions to the theory of optimum allocation of resources" in 1975 [9]. In order to build the dual problem from the original primal problem (1)-(5), the method of Lagrange multipliers [10, p. 229230] was used. The dual problem is presented in (6)-(9):

$$
\begin{gathered}
g(\lambda)=\sum_{i \in I} \lambda_{i}^{1} d_{i}-\sum_{i \in E} \lambda_{i}^{2} e_{i}-\sum_{i, j \in I} \lambda_{i j}^{3} r_{i j} \rightarrow \max \\
c_{i}-\lambda_{i}^{1}+\lambda_{i}^{2} \geq 0 ; i \in E \\
c_{i j}+\lambda_{i}^{1}-a_{i j} \lambda_{j}^{1}+\lambda_{i j}^{3} \geq 0 ; i, j \in I
\end{gathered}
$$


where:

$$
\lambda_{i}^{1}, \lambda_{i}^{2}, \lambda_{i j}^{3} \geq 0 ; i, j \in I
$$

$\lambda_{i}^{1}$ - node prices of gas, $i \in I$

$\lambda_{i}^{2}$ - producer's rent in node $i \in E$

$\lambda_{i j}^{3}-$ transporter's rent for transportation route connecting node $i$ and node $j ; i, j \in I$.

The solutions to problem (6)-(9) are prices in the nodes of gas supply system, producers' and transporters' rent. Node prices assess the value of gas in nodes. Node prices and rent correspond to the problem (1)-(5), ensuring optimal resource allocation. It is worth noting that node prices are not equal to market prices. Actually, market prices reflect many factors that the model does not include. Nevertheless, node prices reflect the facts of competition and limitations of the most cost-effective resources and transport capacities. Therefore, they show price differences in nodes and identify the most competitive and beneficial supply sources for both producers and consumers in market environment. In other words, it means that the price signals from the consumers will be sufficient but not excessive to attract the most cost-effective suppliers. When node prices are higher than production and transportation costs, producers or suppliers receive rent revenues. Rent reflects the scarcity of resources or transport capacities. The sources of rent revenues can be the quality of the production site and its location relative to markets, cost decrease driven by advanced technologies in gas production and transportation.

GEAR model describes perfect competition. Actually, it is a theoretical and unattainable market structure. It is caused by the existence of so-called market imperfections: lack of information and information asymmetry, transaction costs, barriers to entry. The model excludes market manipulation and management of expectations techniques, including through energy derivatives. The model does not take into account the relationships between natural gas and currency markets. The model shows a static equilibrium, while a supply-demand balance is not set immediately. Besides, the model does not reflect directly the factor of interfuel competition. Some elements of market imperfection and the factor of interfuel competition can be included in the model by the modification of the optimization criterion and adding new constrains. Although it is impossible to reflect all elements of market mechanism and market imperfections in the model, the model allows building understanding of market environment changes in case of an emergence of new suppliers and supply routes, changes in demand, technology development, gas production and transportation costs changes.

The role of dual analysis is to evaluate prices and rent on the every link of gas value chain. It points out the most prospective (from rent point of view) production points, supply routes and markets for gas. Besides, the model allows calculating the change of rent if the prices in consumption points or cost change. The following price and rent forces can be analyzed in the dual problem:

1. the development of gas production and transportation technologies;

2 . the changes of maximum production volumes, the launch of new infrastructure facilities or the decommissioning of the existing facilities;

3 . the emergence of new production centers and supply routes;

4. the changes in gas demand;

5. energy policy of the importers, which can consist in the diversification of import sources and supply routes and backing of its own production, including the production from unconventional resources.

\section{Price determinants: the case of unconventional gas development}

Here the development of unconventional gas in gas importing countries is examined to illustrate the opportunities of dual analysis. Fuling gas field, the point of shale gas production located in China, Sichuan province, was added in the model as a new node. This field is the largest shale gas field in the country, accounting for $80 \%$ of China's shale gas reserves $(764.3 \mathrm{bcm})$ [11]. The commercial development of shale gas in China was started from this field, and in 2018 the production from the field reached $6 \mathrm{bcm}$. [12].

The growth of domestic unconventional gas production has impact not only on China's import volumes, but also on gas prices and competitiveness of exporters to the other countries of NEA. Therefore, it is an important factor for all exporters to the region, which include Russia. This version of the model simulates the NEA gas market in 2035. Figure 1 shows node prices (solutions to the problem (6)-(9)) in consumption points as a function of Fuling gas production costs. The highest node prices are in Ulaanbaatar, the lowest node prices are in Wuhan. It is explained by the distances from the production points and the production costs of the nearest suppliers.

The points where the curves $a$ and $b$ cross the node prices curves (fig. 1) show the relationships between the problem (1)-(5) and the problem (6)-(9). When Fuling production costs are lower than 252 US dollars per thousand $\mathrm{m} 3$ maximum production volumes $(60 \mathrm{bcm}$ in this version of the model) are optimal to produce, and when Fuling production costs are higher than 319 US dollars per thousand $\mathrm{m}^{3}$ Fuling gas production is excluded from the solutions to the (1)-(5) problem. When Fuling production costs do not exceed 319 US dollars per thousand $\mathrm{m}^{3}$ Fuling shale gas is competitive in Wuhan, the nearest production point. The higher the costs grow, the less Fuling optimal production volumes are.

While the costs are rising, the production volumes at Fuling gas field are decreasing, and the prices in consumption points are growing. It is worth noting that prices are rising not only in Wuhan, where gas from Fuling 
field is supplied, but also in all of the consumption points. It is reflected in the constraints (8) of the dual problem: the difference between node prices can not exceed the sum of costs to transport gas from one point to another and the rent of transporter. Therefore, if importers want to lower import dependency by domestic unconventional gas production not allowing prices to increase they have to lower the production costs by technology development or subsidize the industry to ensure the competitiveness of unconventional gas. It should be emphasized that the growth of node prices is beneficial for suppliers, because they become more competitive and receive more rent, which is calculated as the difference between prices and costs. The rent of transport is equal to zero in this version of the model, as the constraints (5) do not assume the deficit of transport capacities.

Therefore, the rise of production costs leads to the following consequences:

a) redirection of gas flows and the appearance of more competitive players on the market;

b) the rise of marginal costs and prices in consumption centers, since the supply sources characterized by higher costs are becoming more competitive;

c) the rise of producers rent due to the rise of prices.

\section{Conclusion}

The experience of the use of GEAR model demonstrates that dual analysis could be useful for evaluating price differentials between the points of gas supply system, identifying the most perspective export routs from rent point of view, evaluating the competitiveness of suppliers in different scenarios of technology development, energy policy and market environment.

\section{Acknowledgment}

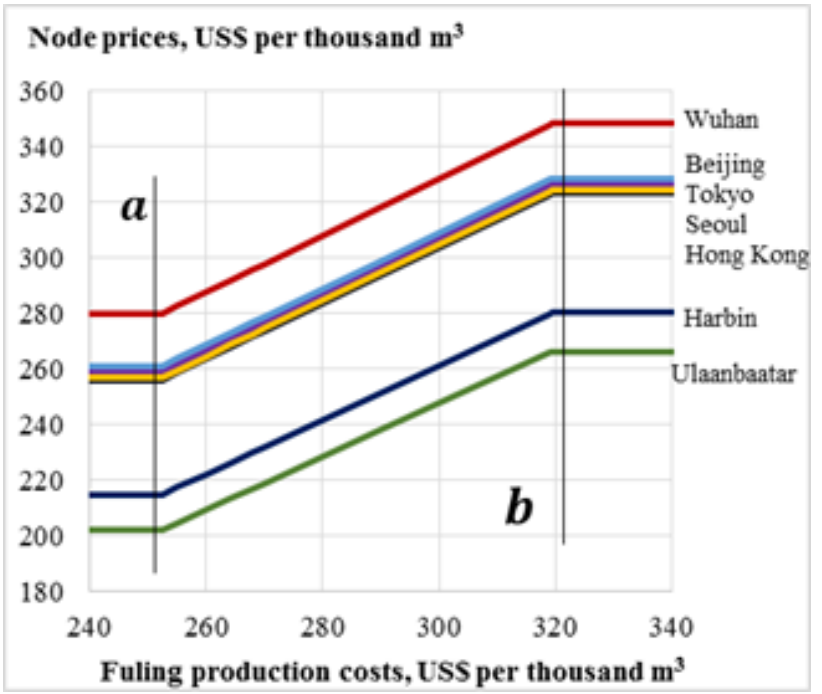

Fig. 1. Node prices in gas consumption points depending on Fuling production costs, in 2017 dollars.
The research was carried out under State Assignment, Project XI.174.2.1 (reg. no. AAAA-A17-1170303104343) of the Fundamental Research of Siberian Branch of the Russian Academy of Sciences.

\section{References}

1. H. Hecking and T. Panke, "COLUMBUS - A global gas market model”, EWI Working Paper, No 12/06. [Online]. Available: $\quad$ https://www.ewi.uni-koeln.de/cms/wpcontent/uploads/2017/01/EWI-WP-12-06-

COLUMBUS\%E2\%80\%93A-global-gas-marketmodel.pdf

2. P. Hartley and K. B. Medlock, "The Baker Institute World gas Trade Model", March, 2015. 59 p. [Online]. Available:

https://www.bakerinstitute.org/media/files/Research/8196 6512/the-baker-institute-world-gas-trade-modelbiwgtm.pdf /

3. International Natural Gas Model 2011, Model Documentation Report, US EIA, USA, 2013. [Online]. Available:

https://www.eia.gov/analysis/pdfpages/ingm(2011)index. php

4. B. Little and M. Fulwood, North American LNG exports: impact on the world gas market. May, 2014. [Online]. Available: https://www.usea.org/event/northamerican-lng-exports-impact-world-gas-market, Accessed on April 26, 2019.

5. Xunpeng Shi and Hari Malamakkavu Padinjare Variam, "Gas and LNG trading hubs, hub indexation and destination flexibility in East Asia," Energy policy, vol. 96, pp. 587-596, 2016. DOI: 10.1016/j.enpol.2016.06.032.

6. World energy markets evolution and its consequences for Russia. Chief Editors A. A. Makarov, L. M. Grigoryev, T. A. Mitrova. Moscow: ERI RAS-ACRF, 2015. 400 p.

7. Ilkevich N., Dzyubina T., Kalinina Zh. Multilevel modeling of the development of gas supply systems. Novosibirsk, Nauka Publ., 2014. 217 p.

8. S. P. Popov, "Gas industry in China: a new resource for development”, Spatial Economics, no. 2, pp. 22-48, 2013. DOI: $10.14530 /$ se.2013.2.022-048.

9. The school of economics. Chief editor M. A. Ivanov. Vol. 1, no. 1. Saint Petersberg, The School of Economics, 1991. 240 p. [Online]. Available: http://mikhailivanov.seinst.ru/journal_of_economic_issue _of the_first_school_of_contents.php, Accessed on April $\overline{2} 6, \overline{2} 01 \overline{9}$.

10. F. P. Vasiliev, Metody optimizatsii [Optimization Methods]. Moskow: Faktorial Press, 2002. 824 p.

11. Prospects for shale gas exploration and development in China are promising. China Geological Survey, 2017. [Online]. Available: http://www.cgs.gov.cn/xwl/cgkx/201712/t20171204_446 411.html, Accessed on April 26, 2019. 
12. Infill wells in Fuling shale gas field have achieved a high level of productivity. Sinopec, 2019. [Online]. Available:

http://www.sinopecnews.com.cn/news/content/2019-

01/31/content_1733288.htm, Accessed on April 26, 2019. 